\title{
Correlation between placental location and maternal fetal outcome
}

\author{
Dhingra S. ${ }^{1}$, Premapriya G. ${ }^{2}$, Bhuvaneshwari K. ${ }^{3}$, Gayathri N. ${ }^{4}$, Vimala D. ${ }^{5}$ \\ ${ }^{1}$ Dr. Sakshi Dhingra, Post Graduate, ${ }^{2}$ Dr. Premapriya. G., Assistant Professor, ${ }^{3}$ Dr. Bhuvaneshwari K., Post Graduate, \\ ${ }^{4}$ Dr. Gayathri. N., Assistant Professor, ${ }^{5}$ Dr. Vimala D, Professor; all authors are affiliated with Vinayaka Mission's \\ KirupanandaVariyar Medical College, Salem, Tamil Nadu, India
}

Corresponding Author: Dr. Premapriya G., Assistant Professor, Department of Obstetrics \& Gynaecology, Vinayaka Mission's Kirupananda Variyar Medical College, Salem, Tamil Nadu, India. E-mail: dr.premapriya.r@gmail.com

\begin{abstract}
Background: Placenta is the vital link between fetus and the uterine wall. Based on location, it can be classified as anterior, posterior, lateral, fundal and low lying. Placental location can be easily determined in the antenatal period using ultrasound. Materials and Methods: Design: Prospective observational study. Study period: One year from January 2018 to February 2019 in a tertiary hospital in Salem district of Tamilnadu. Study population: After informed consent, 200 women with singleton pregnancy of $\geq 28$ weeks attending antenatal OPD were included in the study. Women were followed up with ultrasound at 28 weeks and 34 weeks to identify any maternal and fetal adverse effects such as gestational hypertension, preeclampsia, preterm birth and NICU admission. Results: The mean age of the study participants was $24.3 \pm 43$ years. Of the 200 women, $42 \%(n=84)$ of placenta were situated in fundus, $30 \%(n=60)$ were anterior, $18 \%(\mathrm{n}=36)$ were lateral, $8 \%(\mathrm{n}=16)$ were posterior and $2 \%(\mathrm{n}=4)$ were low lying. Gestational hypertension was present in $22 \%, 13 \%, 12 \%$ in lateral, anterior and posterior placental location respectively. Preeclampsia was seen in $22 \%$ in lateral placental location. Preterm labour, PROM, low birth weight and NICU admission were common in posterior and lateral placental location.Conclusion:There was statistically significant association between low lying, posterior and lateral placental location and adverse maternal fetal outcomes. Hence ultrasound can be used as the safe, cost effective, non-invasive tool in predicting the adverse maternal and neonatal outcome.
\end{abstract}

Keywords: Placental location, Anterior placenta, Posterior placenta, Lateral placenta, Maternal fetal outcome

\section{Introduction}

Placenta is the vital organ which connects fetus to the uterine wall [1]. Nutritive, respiratory, metabolic, endocrine and excretory functions of the fetus are carried out through the placenta. Pregnancy and childbirth itself has health risk to the mother even without pre-existing health problem [2]. In placenta there are two circulations- maternal and fetal. Hence abnormalities in placental location may affect the blood supply of fetus leading to adverse maternal and fetal outcomes such as gestational hypertension, preeclampsia, gestational diabetes, malpresentation, malposition, preterm birth, small for gestational age, intrauterine growth restriction, low birth weight, intrauterine demise, stillbirth etc.,

Placental location is classified as central (anterior and posterior), unilateral (right lateral, left lateral), fundal

Manuscript received: $10^{\text {th }}$ July 2019

Reviewed: $20^{\text {th }}$ July 2019

Author Corrected: $28^{\text {th }}$ July 2019

Accepted for Publication: $2^{\text {nd }}$ August 2019 and low lying (within $2 \mathrm{~cm}$ of internal os). There were only limited studies dealing placental location site and maternal fetal outcome. The hypothesis of this study was whether the placental implantation site predicts the adverse maternal fetal outcome?

Routinely obstetric ultrasound is done in the pregnant women in third trimester to look for fetal growth, amniotic fluid volume and placental location. Ultrasound is the primary modality of choice for placental location assessment. Hence this study was done to find the correlation between placental location and maternal fetal outcome.

\section{Materials and Methods}

Study design: Prospective observational study.

Study period: One year from January 2018 to February 2019 in a tertiary hospital in Salem district of Tamilnadu. 
Inclusion: 200 women with singleton pregnancy of $\geq 28$ weeks attending antenatal OPD were included in the study.

Exclusion criteria: Women with past or present medical and obstetric disorders at the time of study, those not willing for follow up were excluded.

Methodology: Trans abdominal ultrasound was performed to see the placental location using $3.5 \mathrm{MHz}$ convex probe. The same machine was used by the same

\section{Original Research Article}

sonologist for all study participants. Women were followed up with ultrasound for placental location at 28 weeks, 34 weeks to identify any maternal and fetal adverse effects such as gestational hypertension, preeclampsia, premature rupture of membranes, malpresentations, operative delivery, preterm birth and neonatal intensive care (NICU) admission.

Statistics: Statistical analysis was done using SPSS 21. Chi-square test was used for categorical data. P value $<0.05$ is considered as statistically significant.

\section{Results}

The study group consisted of 200 women. The mean age of these women was $24.3 \pm 4.3$ years. Table 1 describes the age distribution of the women in study group. Of the 200 participants, $63 \%(n=126)$ of women were in the age group of 20 to 25 years, $21 \%(n=42)$ were 26 to 30 years, $18 \%(n=9)$ were more than 30 years and $14 \%(n=7)$ were less than 20 years.

Table-1: Age distribution.

\begin{tabular}{|c|c|}
\hline Age in years & $\begin{array}{c}\mathbf{N = 2 0 0} \\
\mathbf{n}(\mathbf{\%})\end{array}$ \\
\hline$<20$ & $14(7 \%)$ \\
\hline $20-25$ & $126(63 \%)$ \\
\hline $26-30$ & $42(21 \%)$ \\
\hline$>30$ & $18(9 \%)$ \\
\hline
\end{tabular}

Table 2 describes the distribution of gravida in the study group. 44\% $(n=88)$ women were primigravida, 43\% ( $\mathrm{n}=86)$ were second gravida, $13 \%(\mathrm{n}=26)$ were third gravida.

Table-2: Gravida distribution

\begin{tabular}{|c|c|}
\hline Gravida & $\begin{array}{c}\mathbf{N}=\mathbf{2 0 0} \\
\mathbf{n}(\mathbf{\%})\end{array}$ \\
\hline 1 & $88(44 \%)$ \\
\hline 2 & $86(43 \%)$ \\
\hline 3 & $26(13 \%)$ \\
\hline
\end{tabular}

Table 3 describes the ultrasound distribution of placental location. Of the 200 women, $42 \%$ ( $n=84)$ of placenta were situated in fundus, $30 \%(n=60)$ were anterior, $18 \%(n=36)$ were lateral, $8 \%(n=16)$ were posterior and $2 \%(n=4)$ were low lying.

Table-3: Ultrasound placental location

\begin{tabular}{|c|c|}
\hline Placental location & $\begin{array}{c}\text { N=200 } \\
\mathbf{n}(\%)\end{array}$ \\
\hline Fundal & $84(42 \%)$ \\
\hline Anterior & $60(30 \%)$ \\
\hline Posterior & $16(8 \%)$ \\
\hline Lateral & $36(18 \%)$ \\
\hline Low lying & $4(2 \%)$ \\
\hline
\end{tabular}

Maternal complications were more in posterior and lateral placental location. Least number of complications was seen in anterior and fundal. 


\section{Original Research Article}

Table 4 describes the distribution of maternal complications. Gestational hypertension was present in $22 \%, 13 \%$, and $12 \%$ in lateral, anterior and posterior placental location respectively. Preeclampsia was seen in $22 \%$ in lateral placental location. Malpresentation such as breech was observed in 50\% of low lying placenta. Premature rupture of membranes (PROM) was common in $12.5 \%$ posterior and $5.5 \%$ lateral placental location.

Table-4: Maternal Outcome.

\begin{tabular}{|c|c|c|c|c|c|c|}
\hline $\begin{array}{l}\text { Maternal } \\
\text { Outcome }\end{array}$ & $\begin{array}{c}\text { Fundal } \\
\mathbf{N}=\mathbf{8 6} \\
\mathbf{n}(\%)\end{array}$ & $\begin{array}{c}\text { Anterior } \\
\begin{array}{c}\mathbf{N}=\mathbf{6 0} \\
\mathbf{n}(\%)\end{array}\end{array}$ & $\begin{array}{c}\text { Posterior } \\
\begin{array}{c}\mathrm{N}=16 \\
\mathbf{n}(\%)\end{array}\end{array}$ & $\begin{array}{c}\text { Lateral } \\
\mathbf{N}=\mathbf{3 6} \\
\mathbf{n}(\%)\end{array}$ & $\begin{array}{l}\text { Low lying } \\
\text { N=4 n(\%) }\end{array}$ & \multirow{5}{*}{$\begin{array}{c}\mathrm{P} \\
0.001 *\end{array}$} \\
\hline $\begin{array}{l}\text { Gestational } \\
\text { hypertension }\end{array}$ & NIL & $8(13 \%)$ & $2(12 \%)$ & $8(22 \%)$ & NIL & \\
\hline Preeclampsia & NIL & NIL & NIL & $8(22 \%)$ & NIL & \\
\hline PROM/PPROM & $2(2.3 \%)$ & NIL & $2(12.5 \%)$ & $2(5.5 \%)$ & NIL & \\
\hline Malpresentation & NIL & NIL & NIL & NIL & $2(50 \%)$ & \\
\hline
\end{tabular}

Normal vaginal delivery was more in fundal and anterior placental location contributing $71 \%$ and $66 \%$ respectively. Operative deliveries such as caesarean were more in low lying, posterior and lateral placental location contributing $100 \%$, $62 \%$ and $61 \%$ respectively.

Table 5 describes the neonatal outcome. Of the neonates, term babies were more in fundal and anterior placenta contributing $97 \%$ and $96 \%$ respectively. Preterm babies were common in low lying, posterior and lateral placental location contributing $50 \%, 37.5 \%$ and $33 \%$ respectively. Low birth weight $<2.5 \mathrm{~kg}$ babies were born in $87.5 \%$ posterior and $77 \%$ lateral placental location. NICU admission was more in low lying $50 \%$ followed by posterior $37.5 \%$ and lateral placental location $22 \%$.P value was $<0.05$ statistically significant. The most common causes for NICU admission includes preterm, low birth weight, respiratory distress syndrome and meconium stained liquor.

Table-5: Neonatal Outcome.

\begin{tabular}{|c|c|c|c|c|c|c|}
\hline $\begin{array}{l}\text { Neonatal } \\
\text { outcome }\end{array}$ & $\begin{array}{c}\text { Fundal } \\
\mathbf{N}=86 \\
\mathrm{n}(\%)\end{array}$ & $\begin{array}{c}\text { Anterior } \\
\begin{array}{c}\mathbf{N}=60 \\
\mathbf{n}(\%)\end{array}\end{array}$ & $\begin{array}{c}\text { Posterior } \\
\begin{array}{c}\mathrm{N}=16 \\
\text { n(\%) }\end{array}\end{array}$ & $\begin{array}{c}\text { Lateral } \\
\mathbf{N}=36 \\
\mathbf{n}(\%)\end{array}$ & $\begin{array}{l}\text { Low lying } \\
\mathrm{N}=4 \mathrm{n}(\%)\end{array}$ & \multirow{4}{*}{$\begin{array}{l}\text { p-value } \\
0.001^{*}\end{array}$} \\
\hline Preterm & $2(2 \%)$ & $2(3 \%)$ & $6(37.5 \%)$ & $12(33 \%)$ & $2(50 \%)$ & \\
\hline $\begin{array}{c}\text { Low birth weight } \\
<2.5 \mathrm{~kg}\end{array}$ & $4(4.6 \%)$ & $4(6.6 \%)$ & $14(87.5 \%)$ & $28(77 \%)$ & NIL & \\
\hline NICU admission & $2(2 \%)$ & $2(3 \%)$ & $6(37.5 \%)$ & $8(22 \%)$ & $2(50 \%)$ & \\
\hline
\end{tabular}

\section{Discussion}

The maternal blood supply to the placenta derives mainly from the uterine arteries. It is not uniformly distributed. In pregnancies with unilateral placentas, uterine artery resistance is lower in the ipsilateral side vs contralateral measured by Doppler velocimetry. The resistance is similar in both sides in centrally situated placenta. There are limited studies showing association between placental location, maternal and fetal outcome.

In the present study fundal placental location was common $84 \%$ followed by anterior, posterior, lateral and low lying placenta. This was similar to Zia $\mathrm{S}$ et al [3]. Gestational hypertension, preeclampsia, Intrauterine growth restriction (IUGR) was more common in lateral placental location. This may be due to non-uniform blood supply. Kolfinas et al, Seadati et al and Singh et al studies reported the same observations [4-6]. This was contrast to Magann et al and Devarajan et al study. They showed no significant association between preeclampsia and lateral placentation $[7,8]$. Booth et al reported the association between fundal placental location and pregnancy induced hypertension [9].

In the present study, preterm labour, increased caesarean deliveries, prematurity, lowbirth weight and NICU admission of babies were statistically associated with low lying placenta followed by posterior and lateral placental location. Mal presentations were common in low lying placenta. This was similar to Rajeswari et al study [10]. 


\section{Original Research Article}

Literature reviews described that posterior placental location is less efficient and associated with preterm labour, Intrauterine demise (IUD) and stillbirth. This was mainly due to uneven blood supply because of the longer, thicker anatomy of posterior wall of pregnant uterus $[11,12]$. Zia $\mathrm{S}$ et al and Torricelli et al and Cho $\mathrm{JY}$ et al found significant association between preterm labour and posterior placental location $(\mathrm{P}<0.001)[3$, $13,14]$. Singh et al, Warland et al and Jaisal et al concluded that posterior placenta was associated with still birth $[6,15,16]$. This was contrast to $\mathrm{Zia} \mathrm{S}$ et al as they found that anterior placenta was associated with IUD [3].

Hadley et al found that fundal placental location increases the risk of premature rupture of membranes. They assumed that fundal placental location has the weakest point of membranes over the cervical os predisposing to premature rupture of membranes [17].

In the study by Nair VV et al, central placental location was most common [18]. Abnormal outcomes such as gestational hypertension, preeclampsia, IUGR, antepartum haemorrhage, preterm delivery, NICU admission was significantly associated with lateral placental location. Singh et al and Kalanithi et al found significant correlation between IUGR and lateral placenta $[6,19]$.

In the present study, NICU admission was more in low lying placenta followed by posterior and lateral placental location. $\mathrm{P}$ value was $<0.05$ statistically significant. Preterm, low birth weight, respiratory distress syndrome and meconium stained liquor are the most common causes for NICU admission. However Zia et al, Jaisal et al and Jackson et al found no association between placental location and NICU admissions $[3,16,20]$.

The limitation of the study is its small sample size. Also it doesn't include gross and intrinsic placental abnormalities.

\section{Conclusion}

Thus in the present study, placental location significantly correlates to the maternal and fetal outcome. Ultrasound is the simple, safe and noninvasive imaging modality to detect placental location. Anterior placenta seems to be safe. Posterior, lateral and low lying placentas were associated with adverse maternal and fetal events. However, more number of prospective studies is needed in future to predict the outcome in this context area of research.

\section{What this study adds in the existing knowledge?}

This study adds to the existing knowledge about the importance of placental location assessment by ultrasoundas a predictor to detect maternal fetal adverse effects at the earliest for its timely intervention.

\section{Author's contribution:}

Dr. Sakshi Dhingra, Dr. Bhuvaneshwari K. collected data. Dr. Premapriya G. and Dr. Gayathri N. performed ultrasound and data analysis. Dr. Premapriya G. drafted the manuscript. Dr. Vimala D. verified. All authors contributed to final manuscript.

Funding: Nil, Conflict of interest: Nil

Permission from IRB: Yes

\section{References}

1. Chhabra S, Yadav Y, Srujana D, Tyagi S, Kutchi I. Maternal neonatal outcome in relation to placental location, dimensions in early pregnancy. J Basic Clin Reprod Sci 2013;2(2):105-9.doi: 10.4103/2278-960X. 118651

2. Priya GP, Veena P, Chaturvedula L, Subitha L. A randomised controlled trial of sublingual misoprostol and intramuscular oxytocin for prevention of postpartum haemorrhage. Arch Gynecol Obstet. 2015;292 (6): 1231-1237. doi: 10.1007/ s00404-0153763-5.

3. Zia S. Placental location and pregnancy outcome. J Turk Ger Gynecol Assoc. 2013;14(4):190-3. doi: 10. 5152/ jtgga.2013.92609.

4. Seadati N, Najafian M, Cheraghi M, Mohammadi B. Placental location at second trimester and pregnancy outcomes. J Pharm SciInnov. 2013;2(2):32-4.

5. Kofinas AD, Penry M, Swain M, Hatjis CG. Effect of placental laterality on uterine artery resistance and development of preeclampsia and intrauterine growth retardation. Am J Obstet Gynecol. 1989;161(6 Pt 1): 1536-9.doi: http://dx.doi.org/10.1016/0002-9378 (89) 90920-4.

6. Singh N, Gupta R, Pandey K, Gupta N, Chandanan A, Singh P. To study second trimester placental location as a predictor of adverse pregnancy outcome. Int $J$ ReproductContracep, Obstet Gynecol. 2016; 6(6): 14147. doi: http://dx. doi.org/10. 18203/2320-1770. ijrcog 20161296 


\section{Original Research Article}

7. Magann EF, Doherty DA, Turner K, Lanneau GS, Jr, Morrison JC, Newnham JP. Second trimester placental location as a predictor of an adverse pregnancy outcome. J Perinatol. 2007;27(1):9-14.doi: http://dx. doi.org/ 10.1038/sj.jp.7211621.

8. Devarajan K, Kives S, Ray JG. Placental location and newborn weight. J ObstetGynaecol Can. 2012;34 (4):325- 9.doi: 10.1016/S1701-2163(16)35212-4.

9. Booth RT, Wood C, Beard RW, Gibson JR, Pinkerton JH. Significance of site of placental attachment in uterus. Br Med J. 1962;1(5294):17324.doi: http://dx.doi.org/10.1136/bmj.1.5294.1732.

10. Rajeshwari RR, Rubini M. Maternal and perinatal outcome in placenta previa - one year study in tertiary care center in Tamil Nadu, India. Int $\mathrm{J}$ Reprod ContraceptObstetGynecol 2016; 5(8): 2819-22.doi: http://dx.doi.org/10.18203/2320-1770.ijrcog 20162673

11. Andersen KV, Munck O, Larsen JF, Kjeldsen H. Placental flow index in posterior wall placentas measured with 99 mtechnecium-labelled human serum albumen. Clinical Physiology. 1983;3(6):577-80.doi: http://dx.doi.org /10.1111/j.1475-097X.1983.tb00867.x.

12. Degani S, Leibovitz Z, Shapiro I, Gonen R, Ohel G. Myometrial thickness in pregnancy: Longitudinal sonographic study. J Ultrasound Med. 1998;17 (10): 661-5. doi: https://doi.org/10.7863/jum.1998.17.10.661

13. Torricelli M, Vannuccini S, Moncini I, Cannoni A, Voltolini C, Conti N, et al. Anterior placental location influences onset and progress of labor and postpartum outcome. Placenta. 2015;36(4):463-6.doi: 10.1016/j. placenta. 2014.12.018.
14. Cho JY, Lee YH, Moon MH, Lee JH. Difference in migration of placenta according to the location and type of placenta previa. J Clin Ultrasound. 2008;36(2):7984. doi: http://dx.doi.org/10.1002/jcu.20427.

15. Warland J, McCutcheon H, Baghurst P. Placental position and stillbirth: a case-control study. Journal of Clinical Nursing. 2009;18(11):1602-6.doi: http://dx.doi. org/10.1111/j.1365-2702.2008.02779.x

16. Jaisal P, Bhonsale D. Association of Placental Localization at 16-24 Week and Pregnancy Outcome. Int J Med Res Prof. 2016;2(4):7-9. 8.http://dx.doi.org/ 10.21276/ijmrp.2016.2.4.002.

17. Hadley CB, Main DM, Gabbe SG. Risk factors for premature rupture of the fetal membranes. Am J Perinatol. 1990;7(4):374-9.doi: http://dx.doi.org/10. $1055 /$ s-2007-999527.

18. Nair VV, Nair SS, Radhamany K. Study of placental location and pregnancy outcome. Int J Reprod Contracept Obstet Gynecol 2019; 8(4): 1393-7. doi: http:// dx.doi.org/10.18203/2320-1770.ijrcog 20191187

19. Kalanithi LE, Illuzzi JL, Nossov VB, Frisbaek Y, Abdel-Razeq S, Copel JA, et al. Intrauterine growth restriction and placental location. J Ultrasound Med. 2007; 26 (11):1481-9. doi:10.7863/jum.2007. 26.11. 1481.

20. Jackson R, Carson M, Melamed N, Barrett JF, Mei Dan E. 469: The impact of placental location on neonatal adverse outcomes. Am J Obstet Gynecol. 2018; 218(1):S282.doi:https://doi.org/10.1016/j.ajog. 2017. 10.405.

\section{How to cite this article?}

Dhingra S, Premapriya G, Bhuvaneshwari K, Gayathri N, Vimala D. Correlation between placental location and maternal fetal outcome. Obs Rev: J obstet Gynecol 2019;5(3):128-132.doi:10.17511/joog.2019.i03.01. 